\title{
Fluorine F 18-VM4-037
}

National Cancer Institute

\section{Source}

National Cancer Institute. Fluorine F18-VM4-037. NCI Thesaurus. Code C85449.

A radiopharmaceutical consisting of a sulfonamide covalently attached to the positronemitting isotope fluorine F 18 with CA-IX-binding and radioisotopic activities. Upon administration, the sulfonamide moiety of [F18]VM4-037 binds to the cell-surface tumorassociated antigen (TAA) carbonic anhydrase IX isoenzyme (CA-IX); CA-IX-expressing tumor cells can then be visualized using positron emission tomography (PET). CA-IX has been found to be elevated in a variety of hypoxic tumors; elevated CA-IX has been positively correlated with tumor growth, tumor invasion and poor prognosis. 